\title{
INFLUENCE OF ADJUSTABLE FRONT BALLAST ON TRACTOR AXLES BALANCE
}

\author{
Vidas Damanauskas \\ Lithuanian Research Centre for Agriculture and Forestry, Lithuania \\ damvid@gmail.com
}

\begin{abstract}
Ordinarily a tractor works under variable load conditions, what brings unavoidably changing deformations of the tractor front and rear tires, which affects the front and rear axis height. This situation causes problems when the height of the suspended implement must be constant, especially during the crop fertilization operation. The spreader mass is changed from maximum when it is full of fertilizer to minimum when it is empty. The changeable mass of the suspended sprayer induces an uncertain mass centre point of the tractor. Mass transfer changes the height of the tractor axles, with the suspended spreader towards changeable position spreading of fertilizers is inappropriate, because the spread width is unstable. For solving such impact of mass transfer a special attachment of the front ballast with a possibility to change its forward distance was made. The aim of the research was to establish how much the adjustable front ballast can adjust the heights of the front and rear axis of the tractor and to maintain a constant spreader height. The investigative tractor "Ford 8340" and fertilizer spreader "BogballeEX Trend" were used in the research. Mathematical method was applied for the search potential of ballast that can generate an appropriate weight transfer of the front and rear axis load. This study has developed the correlation of the adjustable front ballast and the tractor axle height balance, and spreading quality during the crop fertilizing operation. The results show that the adjustable front ballast can reduce the mass transfer between the tractor axles, compensate the height of the front and rear axis and improve the distribution of fertilizers in the application width by 10-15\% compared to the case when the front ballast was used by default.
\end{abstract}

Keywords: variable load, mass transfer, axis height, ballast position.

\section{Introduction}

In most of the researches the tractor ballast was used to assure efficient work and safe driving [13]. Front ballast prevents front driving wheels from slipping, as well as overturning the tractor backwards [4]. This is mostly relevant when the implement is suspended. As known, the tractor works under variable drawbar and implement load conditions which causes mass transfer $[5 ; 6]$. The load changes on the front and rear axis changed the deflection of the front and rear tires of the tractor. Depending on the tractor configuration, e.g. the size of the ballast, the tire inflation pressure and the additional load by the attached implement, this causes the height of the tractor tire and linear speed ratio of wheels as much as $5 \%$ [7]. Appropriate front ballast may adjust the front and rear wheel linear speed ratios and assure correct kinematic disappearance [8; 9]. This disproportionate tire deflection causes the variation of the axis height and complications occur when the height of the suspended implement must be constant, for example, at spreading fertilizes. In fertilizing works the mass of the spreader varies when it is full or empty. Consequently, the fertilizer spreader height varies too, the spreading width becomes unstable. To prevent this from happening the ballast weight should be changed if the working conditions are changed. Variable waterballast was investigated by Clark and Vande Linde developing a computer-controlled system, which could fill or empty 1401 ballast tanks over each wheel of $180 \mathrm{~kW}$ tractors within a period of $10 \mathrm{~min}$. They used water contained in a supply tank in a field going trailer, which also carried the pump and valve system [10]. Self et al. equipped a $130 \mathrm{~kW}$ four-wheel-drive tractor with a rear-mounted ballast rack, which could be pivoted in a foreand-aft mode by a hydraulic cylinder so that the proportion of total static weight on the front axle could be changed in the range from 35 to $47 \%$ [11]. Dodd et al. developed a computer-controlled system to adjust the geometry of a three-point hitch so that the position of the virtual hitch point of a mounted implement could be changed as the tractor was operating. The system moved the virtual hitch point to the rear (essentially increasing the vertical angle to the implement centre of resistance) as draft forces increased and vice-versa. This increased weight transfer to the rear tractor wheels as draft increased, but also increased the vertical force component on the implement [12]. Slipping problem can be solved by appropriate ballasting of the tractor [13; 14]. The authors examined the influence of ballast on tractive performanceor front loader mass balancing [15; 16], but the influence of the ballast weight on axis height has not been examined. The problem considered in this research is the mass transfer of the aggregate what changes the heights of the tractor axles and the spreader. For solving such impact of mass transfer a special ballast positioning systemwas made. This research investigate 
shows much the front ballast position can adjust the heights of the front and rear axis of the tractor. The study serves an accurate use of fertilizers applied in precision farming.

\section{Materials and methods}

The investigative tractor "Ford 8340" and fertilizer spreader "Bogballe EX Trend" were used in this research. According to the tire load and tire data sheet chart, the tire inflation pressure value was $23 \mathrm{psi}\left(1.6 \mathrm{~atm} \cdot \mathrm{cm}^{-2}\right)$.

Table 1

\section{Tractorand spreader parameters}

\begin{tabular}{|l|l|}
\hline Weight of the tractor & $5566.7 \mathrm{~kg}$ \\
\hline Front tires & Petlas 440/65 R24 \\
\hline Rear tires & Alliance 18.6 R38 \\
\hline Wheelbase & $2.6 \mathrm{~m}$ \\
\hline Hitch point from rear axle & $1.7 \mathrm{~m}$ \\
\hline Mass of spreader "Bogballe" & $361.3 \mathrm{~kg}$ \\
\hline
\end{tabular}

The measurements were made: a) weight of the tractor axis; b) height of the tractor axis by measuring each of the axle's height; c) the fertilizing quality tests were accomplished by measuring the weight of fertilizers in boxes placed every meter. The mathematical modelling was used for predicting of the tractor weight transfer distance and estimating the impact of the forward distance of the ballast mass at various spreader weights. The ballast positioning system must keep the same weight distribution on axis.

The distance of the mass centre from the rear axis:

$$
L_{W}=\frac{m_{f} \cdot L}{W},
$$

where $W$ - tractor mass;

$L_{W}$ - distance of the mass centre from the rear axis;

$m_{f}-$ mass on the front axis;

$L$ - base of the tractor.

Total mass centre transfer:

$$
\Delta L_{W}=\frac{m_{f \max } \cdot L}{W_{\min }}-\frac{m_{f \min } \cdot L}{W_{\text {max }}},
$$

where $m_{f \max }-$ maximum load on the front axis;

$m_{f \min }-$ minimum load on the front axis;

$W_{\min }-$ tractor weight with empty spreader;

$W_{\max }-$ tractor weight with full spreader;

$L$ - base of the tractor.

The dependence of the forward distance of the ballast $\left(L_{1}\right)$ on the spreader weight $\left(M_{F}\right)$, when there is no weight transfer:

$$
L_{1}=\frac{M_{B} \cdot L_{2}}{M_{F}},
$$

where $M_{B}$-ballast mass;

$L_{2}$ - distance of the spreader mass point;

$M_{F}$ - mass of fertilizer.

The deflection $(f)$ of tires was measured as shown in Figure 1. According to Hedekel'sequation, the deformation of the tire is given by the following (Figure 2):

$$
f=\frac{F}{2 \cdot \pi \cdot p_{i} \cdot \sqrt{R \cdot r}},
$$


where $F-$ vertical load of the wheel;

$p_{i}$ - tire air pressure;

$R$ - free radius of the wheel;

$r$ - radius of the tire running path in cross section.

The static wheel radius is given by:

$$
R_{s}=R-f,
$$

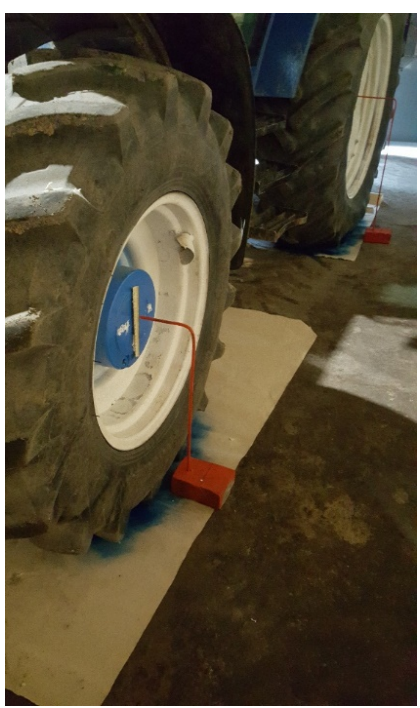

Fig. 1. Measuring of axis height

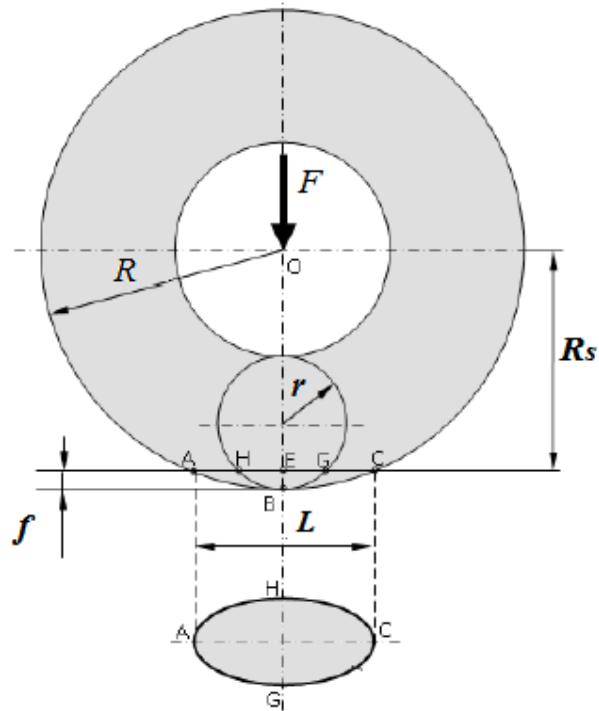

Fig. 2. Deformation of tire

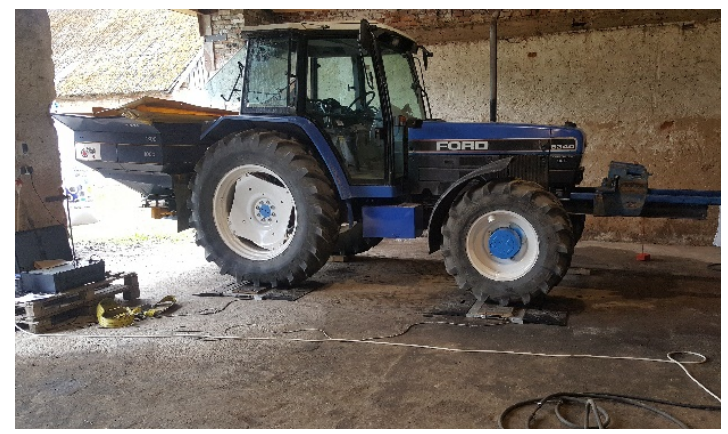

Fig. 3. Measuring of axis weight

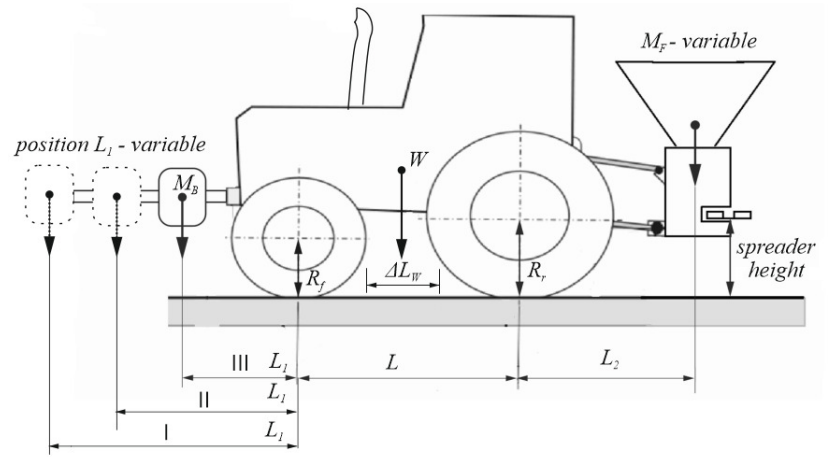

Fig 4. Scheme of aggregate: $L_{2}=1.7 \mathrm{~m}, M_{B}=500 \mathrm{~kg}$

The fertilizer quantity samples from each treatment of the ballast position mode were taken manually after spreading. The fertilize was collected from 20 boxes (each of $0.25 \mathrm{~m}^{2}$, placed every meter across of tramlines) and was weighted with the scales "Kern EW1500-2M error $\pm 0.01 \mathrm{~g}$.

The value of fertilize spreading uniformity was calculated as the ratio of fertilizer mass in the middle and side part of the spreading width and marked $k_{i}$ :

$$
k_{i}=\frac{M_{s}}{M_{m}},
$$

where $M_{s}$ - mass of fertilizer in the side box;

$M_{m}$ - mass of fertilizer in the middle box.

The measurement data of the fertilizer mass $M_{s}, M_{m}$ standard deviation did not exceed 5 percent of one regime treatment. The statistical (ANOVA) analysis of the results showed significant differences between the ballast position mode combinations $\left(F>F_{c r i t}\right)$ of fertilizers applied by three replications. 


\section{Results and discussion}

The changeable mass of the suspended sprayer induces an uncertain mass centre point of the tractor. The load of the suspended implement makes significant weight transfer of the tractor. Weight transfer changes the height of the tractor axles because of tire deformations. With the suspended spreader towards changeable position, spreading of fertilizers becomes inappropriate, because the spread width also becomes unstable. The research investigated that the front ballast positioning system can slightly adjust the mass distribution on the front and rear axis of the tractor. With the ballast positioning system the weight of the front axis varied from 1190 to $3044 \mathrm{~kg}$, the weight of the rear axis varied from 2523 to $6846 \mathrm{~kg}$. Measurements were done by the scales Portable Axe Weigher WPD-2 at three repeatings of the position of the ballast distance and spreader load. The axis weight data deviation of measurements of replications did not overrun $2 \%$.

The results show that the mass balance on the tractor axis varied from 54.7/45.3 to 14.8/85.2\% When the tractor was without the spreader, the mass balance on the axis varied from 50.8/49.2 to $54.7 / 45.3 \%$; with full spreader the mass balance on the axis varied from 14.8/85.2 to17.4/82.6\%. The weight balances, shown in Table 1, were maintained by variations of the front ballast position and spreader mass.

Table 2

\section{Weight distribution and balance on axis in dependence on fertilizer mass}

\begin{tabular}{|c|c|c|c|c|c|c|}
\hline \multirow{2}{*}{$\begin{array}{c}\text { Ballast } \\
\text { position }\end{array}$} & \multicolumn{3}{|c|}{ Axis weight without spreader, kg } & \multicolumn{3}{c|}{ Axis weight with empty spreader, kg } \\
\cline { 2 - 7 } & front & rear & balance \% & front & rear & balance \% \\
\hline I & 3044 & 2523 & $54.7 / 45.3$ & 2712 & 3216 & $45.7 / 54.3$ \\
\hline II & 2935 & 2631 & $52.7 / 47.3$ & 2604 & 3324 & $43.9 / 56.1$ \\
\hline III & 2825 & 2741 & $50.8 / 49.2$ & 2496 & 3432 & $42.1 / 57.9$ \\
\hline \multirow{2}{*}{$\begin{array}{c}\text { Ballast } \\
\text { position }\end{array}$} & \multicolumn{3}{|c|}{ Axis weight with } & \multicolumn{3}{c|}{ Axis weight with } \\
\cline { 2 - 7 } & 1000 kg of fertilizer, kg & \multicolumn{2}{c|}{ 2000 kg of fertilizer, kg } \\
\hline front & rear & balance \% & front & rear & balance \% \\
\hline I & 2132 & 5024 & $29.8 / 70.2$ & 1401 & 6635 & $17.4 / 82.6$ \\
\hline II & 2020 & 5136 & $28.2 / 71.8$ & 1296 & 6740 & $16.1 / 83.9$ \\
\hline III & 1908 & 5248 & $26.7 / 73.3$ & 1190 & 6846 & $14.8 / 85.2$ \\
\hline
\end{tabular}

Note: I -maximum length ballast position; II - middle ballast position; III - default ballast position.

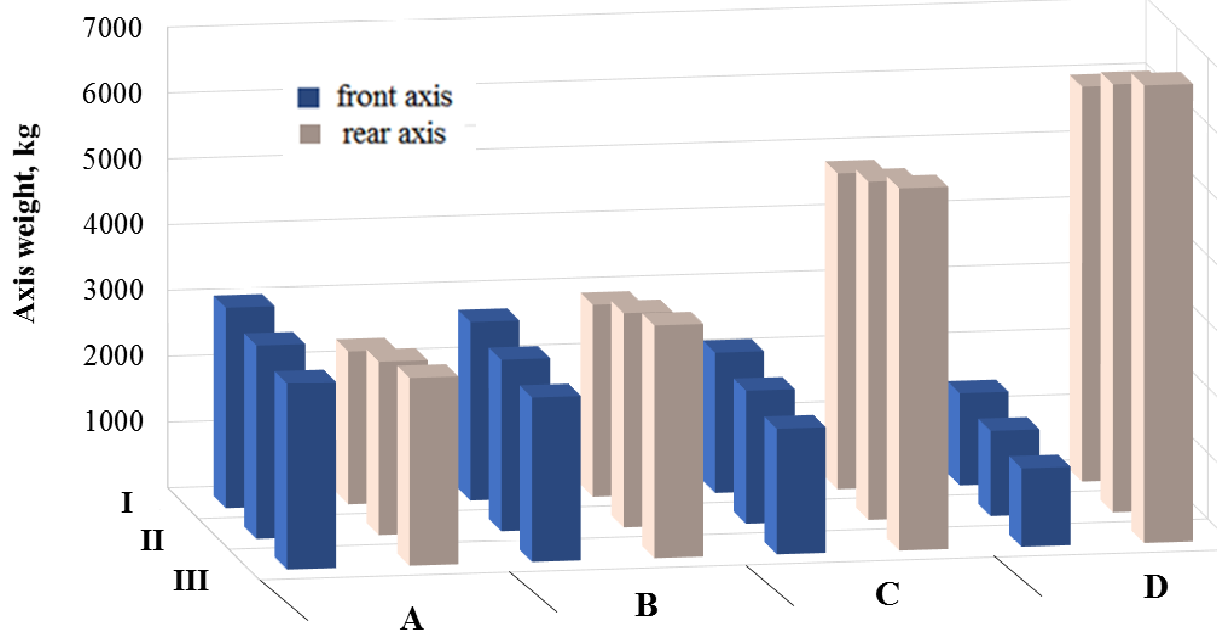

Fig. 4. Dependence of front adjusting ballast and sprayer mass on axis load

Note: A - tractor axis load without spreader; B - tractor axis weight with empty spreader; C - tractor axis weight with $1000 \mathrm{~kg}$ fertilizers; D - tractor axis weight with $2000 \mathrm{~kg}$ fertilizers; I -maximum length ballast position; II - middle ballast position; III - default ballast position 
New design tires are more flexible and might deform more. Weight transfer changes the height of the tractor axles because of tire deformations. In our case, on dependence of the weight of the suspended spreader, the maximum deformation value of rear tires was $4 \pm 0.2 \mathrm{~cm}\left(R_{r}=\right.$ from 81 to $77 \pm 0.2 \mathrm{~cm})$ and front tires $2 \pm 0.2 \mathrm{~cm}\left(R_{f}=\right.$ from 58 to $\left.56 \pm 0.2 \mathrm{~cm}\right)$. The research determined that the front ballast positioning system can slightly adjust the axis height. It was found that the spreader height varied $5 \pm 0.2 \mathrm{~cm}$, on dependence if it is empty or full at constant ballast position. The height of the spreader varied about $3 \pm 0.2 \mathrm{~cm}$ by variation of the ballast position. When the ballast is towed to the maximum length position, at full spreader the height of the spreader was $85 \pm 0.2 \mathrm{~cm}$, then the ballast is toward the middle position, when the spreader is half full of fertilizers, the height of the spreader was $86 \pm 0.2 \mathrm{~cm}$, then the ballast is toward the default position, when the spreader is empty, the height of the spreader was $87 \pm 0.2 \mathrm{~cm}$. Height measurements with ruler were performed by repeating loading of the fertilizers into the fertilizer spreader by three replications.

Table 3

Dependence of sprayer height on fertilizer mass

\begin{tabular}{|l|c|c|c|}
\hline \multirow{2}{*}{ Position of ballast } & \multicolumn{3}{|c|}{ Spreader height, cm } \\
\cline { 2 - 4 } & $0 \mathrm{~kg}$ & $1000 \mathrm{~kg}$ & $2000 \mathrm{~kg}$ \\
\hline I - maximum length & 90 & 87.5 & 85 \\
\hline II - middle & 88.5 & 86 & 83.5 \\
\hline III - default & 87 & 84.5 & 82 \\
\hline
\end{tabular}

The quality of spreading fertilizers depends on spreading uniformity. At the beginning of crop field fertilizing, when the spreader is full, fertilizers are distributed unevenly because the height of the spreader decreased, the width of spreading fertilizers decreased, too. The overall fertilizer quantity in the whole application width was the same but distributed inappropriately. Thus, the fertilizer quantity in the middle of the tramline was higher than supposed to be. The fertilizer quantity in the edge of the tramline was lower than supposed to be. At the end of fertilizing, when the spreader empties, the quantity of fertilizers at the edges of the tramline is higher than supposed to be, but at the middle part the quantity is lower than supposed to be. Furthermore, from visual comparison of plants, this repetitive uneven fertilizing has negative impact on crop growing.

The comparative indicator of fertilizer spreading quality was the fertilizer mass ratio in the middle part and in the edge of the tramline and it was used as a uniformity indicator. The uniformity indicator $k_{i}$ varied from 0.24 to 0.56 depending on the mass balance of the aggregate. The results of the fertilizer mass in sample boxes, with data deviation $\pm 0.08 \mathrm{~g}$, are presented it Table 4 .

Table 4

Fertilizer uniformity and indicator $\boldsymbol{k}_{i}$

\begin{tabular}{|c|c|c|c|c|c|c|c|c|c|}
\hline \multirow{2}{*}{$\begin{array}{c}\text { Ballast } \\
\text { position }\end{array}$} & \multicolumn{4}{|c|}{$\begin{array}{c}\text { Fertilizer mass in boxes } \\
\text { when spreader almost } \\
\text { empty, }\end{array}$} & \multicolumn{2}{c|}{$\begin{array}{c}\text { Fertilizer mass in boxes } \\
\text { when spreader half full, g }\end{array}$} & \multicolumn{2}{|c|}{$\begin{array}{c}\text { Fertilizer mass in boxes } \\
\text { whenspreaderfull, g }\end{array}$} \\
\cline { 2 - 10 } & edge & middle & $k_{i}$ & edge & middle & $k_{i}$ & edge & middle & $k_{i}$ \\
\hline I & 2.7 & 4.8 & 0.56 & 2.2 & 5.6 & 0.39 & 1.8 & 6.2 & 0.29 \\
\hline II & 2.5 & 5.1 & 0.49 & 2.1 & 5.7 & 0.37 & 1.7 & 6.5 & 0.26 \\
\hline III & 2.3 & 5.4 & 0.43 & 2.0 & 6.0 & 0.33 & 1.6 & 6.7 & 0.24 \\
\hline
\end{tabular}

Note:I -maximum length ballast position; II - middle ballast position; III - default ballast position.

\section{Conclusions}

The results of this study may provide helpful indications for tractor's work with suspended implement, optimize ballast load requirement at spreading of fertilizer application, as a result improve crop fertilization.

1. Based on the results, when the fertilizer mass varied from 0 to $2000 \mathrm{~kg}$, the front axis load change was $1306 \mathrm{~kg}$ and the rear axis load change was $3414 \mathrm{~kg}$, when the front ballast was used by default. With the ballast positioning system the mass change of the front axis was $1095 \mathrm{~kg}$, and the mass change of the rear axis was $3203 \mathrm{~kg}$. From this we can see that the ballast positioning 
system can decrease tire overload. The weight balance ratio varied from 42.1/57.9 to $14.8 / 85.2$ when ballast was used by default. With the ballast positioning system the weight balance ratio was 17.4/82.6 at full spreader and longer ballast position, it is almost equal to the required safety balance ratio.

2. The ballast positioning system was effective in maintaining the desired level of the axle height under varying load conditions. By adjusting the forward distance of the front ballast, the compensation of the axis height was achieved. The spreader height, when it is empty or full, changed only $2 \pm 0.2 \mathrm{~cm}$.

3. From the data obtained here it might be expected that the ballast positioning system could result in improvements at any field work. The fertilizer spraying quality level, which in this case was considered the fertilizer mass ratio, by using the ballast positioning system was improved by 10 $15 \%$ compared to the case when the front ballast was used by default.

The following test for avoiding of weight transfer would require a higher mass or longer possible forward distance of the ballast. The best option of keeping the implement height constant would be a trailed implement, which has its own wheels and is not influenced by the tractor axle position.

\section{Acknowledgement}

This research is supported by the research programme "Productivity and sustainability of agricultural and forest soils" implemented by the Lithuanian Research Centre for Agriculture and Forestry.

\section{References}

[1] Sharma A.K., Pandey K.P. Matching tyre size to weight, speed and power available for maximising pulling ability of agricultural tractors, Journal of Terramechanic 38, No 2, 2001, pp. 89-97.

[2] Gee-Clough D, Pearson G, McAllister M. Ballasting wheels tractors to achieve maximum power output in frictional-cohesive soils. Journal of Agricultural Engineering Research vol 27, 1982, pp. 1-19.

[3] Damanauskas V., Janulevičius A. Differences in tractor performance parameters between singlewheel 4WD and dual-wheel 2WD driving systems. Journal ofTerramechanic 60, 2015, pp. 63-73.

[4] Rondelli V., Guzzomi A.L. Selecting ROPS safety margins for wheeled agriculturaltractors based on tractor mass. Biosystems engineering 105, 2010, pp. 402-410.

[5] Lee J.W., Kim K.U., Kim D.H., Choi K.J. Effects of distribution of axle load and tyre inflation pressures on fuel efficiency of tractor operations.Journal of Biosystems Engineering 36, No5, 2011, pp. 303-313.

[6] Polcar A., Renčín L., Votava J. Drawbar pull and its effect on the weight distribution of a tractor. Acta Univ. Agric. Silvic. Mendelianae Brun., 65, 2017, pp. 145-150.

[7] Janulevičius A., Damanauskas V., Pupinis G. Effect of variations in front wheels driving lead on performance of a farm tractor with mechanical front-wheel-drive. Journal of Terramechanics, 77, 2018, pp. 23-30.

[8] Zoz F. M., Grisso R. D. Traction and Tractor Performance. Transactions of the ASAE, Lecture Nr 27, 2003, pp. 1-44.

[9] Burt EC, Bailey AC. Load and inflation pressure effects on tyres. Transactions of the ASAE, vol 25, No 4,1982, pp. 881-884.

[10] ClarkR. L., Vande LindeG. A rapid automatic tractor ballast system. Transactions of the ASAE. vol 36, No 5, 1993, pp. 1261-1266.

[11] Self, K.P., J.D. Summers and G.L. McLaughlin. 1987. Instrumentation for determining fourwheel drive tractor performance. ASAE Paper No. 87-1029. St. Joseph, MI: ASAE

[12] Dodd, R.B., D. Wolf, T.H. Garner, S.A. Hale and V.R. Pieper. 1986. Preliminary design and testing of a variable geometry three-point hitch. ASAE Paper No. 86-1085. St. Joseph.

[13]Zhang N., Chancellor W. Automatic ballast position control for tractors. Transactions of the ASAE,vol. 32, 41989, pp. 1159-1164. 
[14] Battiato A., Diserens E. Influence of tyre inflation pressure and wheel load on the traction performance of a $65 \mathrm{~kW}$ MFWD tractor on a cohesive soil - Journal of Agricultural Science, vol 5, No 8, 2013, pp. 197-215.

[15] Pranav P.K., PandeyK.P. Computer simulation of ballast management for agricultural tractors. Journal of Terramechanic vol. 45, Issue 6, 2008, pp. 185-192.

[16] Thiruselvan M. G, Kumar R. P., Prabu P., Harishbabu B. Design optimisation of counter weight of front-end loader through dynamic mass balancing. International Journal of Engineering Research \& Technology (IJERT) 2014. Vol. 3 No 3 pp. 929-931. 